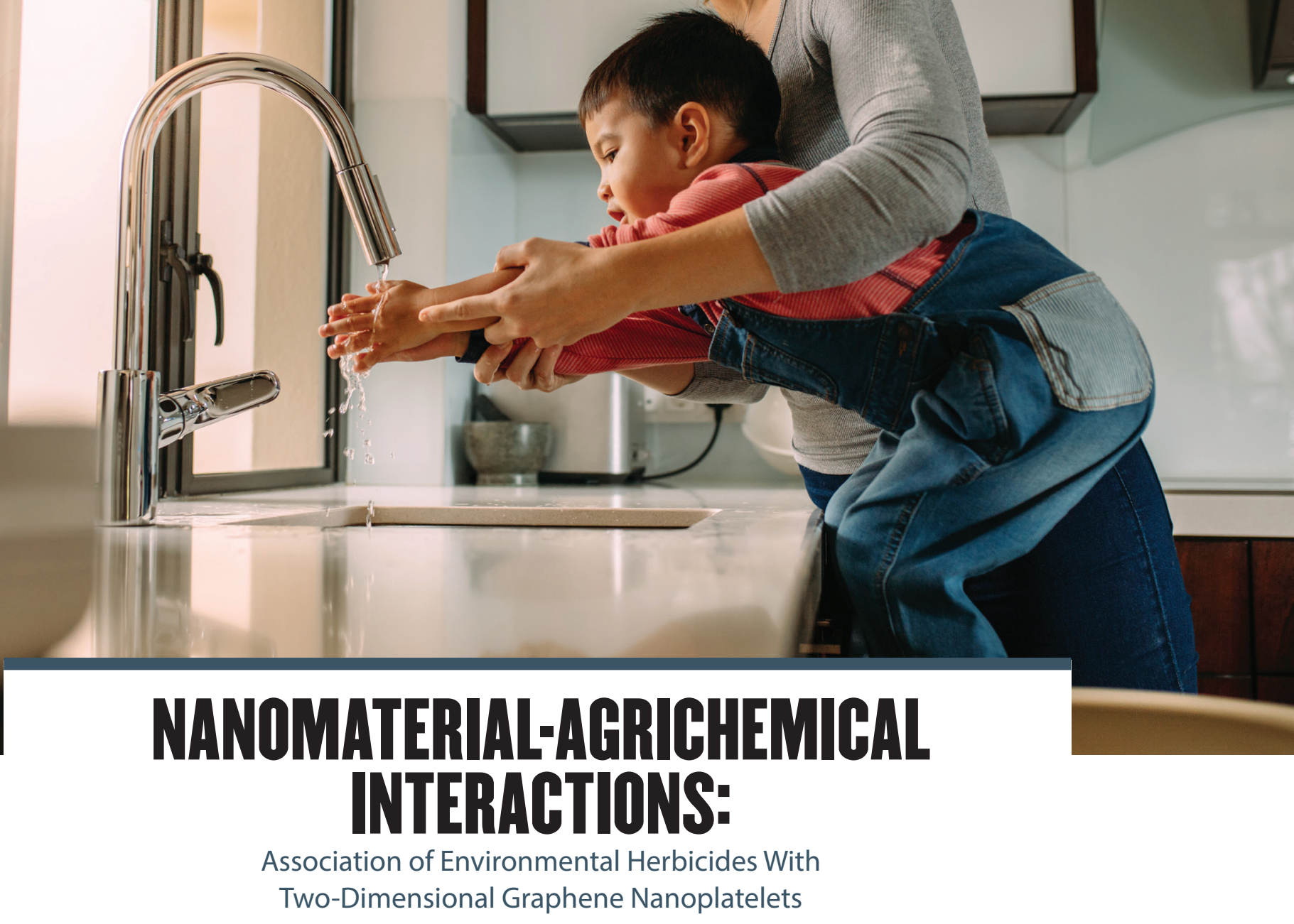

Student Author

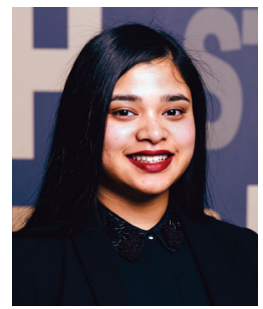

Nudar A. Bhuiya is a senior in the College of Health and Human Sciences and Purdue Honors College. She graduated in May 2019 with a bachelor of science in health sciences preprofessional. Bhuiya has been working in the Freeman and Shannahan laboratories since 2017 studying the binding interactions between graphene nanoplatelets and various herbicides, such as atrazine and glyphosate. The main aim of her research is to determine whether graphene nanoplatelets can be used for environmental remediation of herbicide contamination. After graduation, Bhuiya plans to pursue a degree in medicine at the Indiana University School of Medicine in the fall of 2019.

Mentors

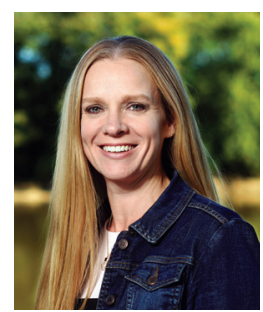

Jennifer L. Freeman is an associate professor of toxicology in the School of Health Sciences. Dr. Freeman received her $\mathrm{PhD}$ in environmental toxicology and molecular cytogenetics from the University of Illinois at
Urbana-Champaign and was a postdoctoral fellow at Harvard Medical School and Brigham and Women's Hospital. Current research efforts in the Freeman laboratory are defining the underlying genetic and epigenetic mechanisms of a developmental exposure to environmental chemicals including pesticides, metals, and other legacy and emerging contaminants using the zebrafish vertebrate model system. These studies are investigating a developmental origin of health and disease pathogenesis and transgenerational consequences with a specific focus on neurological disease, reproductive dysfunction, and cancer with the goal of understanding the role of exposure to the environmental stressors in these adverse health outcomes.

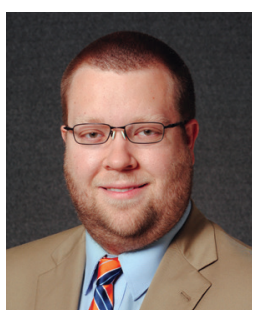

Jonathan H. Shannahan is an assistant professor of toxicology in the School of Health Sciences. Dr. Shannahan received his $\mathrm{PhD}$ in toxicology from the University of North Carolina-Chapel Hill and completed his postdoctoral training at the University of Colorado-Anschutz Medical Campus. The Shannahan research laboratory examines mechanisms of susceptibility to exposures in individuals suffering 
from prevalent disease conditions. Many of the laboratory's ongoing projects evaluate immune, cardiovascular, and pulmonary toxicity associated with engineered nanomaterial exposures. Overall the goal of these studies is to mitigate adverse public health effects, elucidate mechanisms of toxicity, and provide necessary information for the safe and effective usage of nanotechnology.

\section{Abstract $\mathbb{N}$}

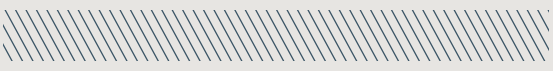

Atrazine and glyphosate are the two most common agricultural herbicides used in the United States. Both herbicides can move in the environment, which results in contamination of drinking water sources. Graphene nanoplatelets (GNPs) are an emerging nanoparticle with potential uses for the remediation of environmental contamination. The first aim of this study was to determine binding interactions between atrazine and GNPs to mimic a mixture composition. To determine binding interactions, GNPs with different functional groups (none, carboxylated, or aminylated) were evaluated. GNPs at concentrations of $0,0.5,1,2$, or 3 $\mathrm{mg} / \mathrm{ml}$ were incubated with atrazine at $3 \mathrm{ppb}$ $(\mu \mathrm{g} / \mathrm{L})$ and centrifuged, allowing a supernatant to be collected. The supernatant was used to quantify the concentration of atrazine using an Abraxis Atrazine ELISA assay. The data demonstrated that as the concentration of GNPs increased, the percentage of atrazine bound increased until it plateaued at $2-3 \mathrm{mg} /$ $\mathrm{ml}$ of GNPs. The nonfunctionalized GNPs (N-GNPs) bound the most atrazine compared to the functionalized GNPs. The final aim of this study was to determine whether GNPs can be used as a tool for environmental remediation of atrazine and glyphosate contamination. Mixtures involving N-GNPs (1 $\mathrm{mg} / \mathrm{ml})$ and the herbicides atrazine ( $3 \mathrm{ppb}$ ) and glyphosate $(700 \mathrm{ppb})$ were created to mimic environmental conditions. The mixtures were treated with a similar protocol as the first aim. This experiment demonstrated that N-GNPs bind to atrazine, while binding does not occur between glyphosate and N-GNPs. In addition, glyphosate did not interfere with the binding between atrazine and N-GNPs.
Bhuiya, N. A. (2019). Nanomaterialagrichemical interactions: Association of environmental herbicides with twodimensional graphene nanoplatelets. Journal of Purdue Undergraduate Research, 9, 2-8. https://doi.org/10.5703/1288284316926

\section{Keywords}

nanoparticles, graphene nanoplatelets, herbicides, atrazine, glyphosate

\section{INTRODUCTION}

Atrazine (6-chloro-4-N-ethyl-2-N-propan-2-yl-1,3,5triazine-2,4-diamine) is one of the most commonly used herbicides in the United States ("Atrazine," 2019; Fakhouri, Nuñez, \& Trail, 2010) (Figure 1). This herbicide is used extensively in the Midwest region of the United States in order to prevent the growth of grassy weeds and broadleaf plants in certain crops (Wirbisky et al., 2015). Because of its widespread use, atrazine has appeared in drinking water sources often at concentrations above the maximum contaminant level (MCL) of 3 parts per billion $(\mu \mathrm{g} / \mathrm{l})$ set by the U.S. Environmental Protection Agency (EPA) (Gilliom, Geological Survey, \& National Water-Quality Assessment Program, 2006; Thurman, Goolsby, Meyer, \& Kolpin, 1991). In 2004, the European Union banned the use of atrazine due to risk of environmental contamination (European Commission, 2013). Furthermore, atrazine is a possible endocrine disrupting chemical (Wirbisky et al., 2016).

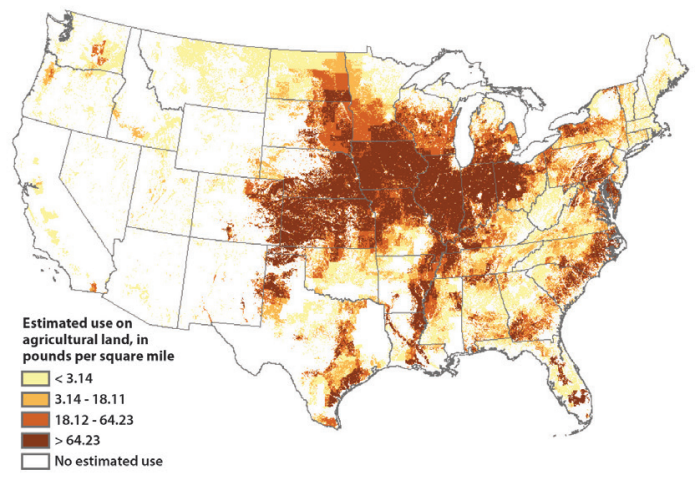

Figure 1. The estimated use of atrazine for agricultural purposes in 2016 (preliminary, EPest-Low) (USGS, 2018). 


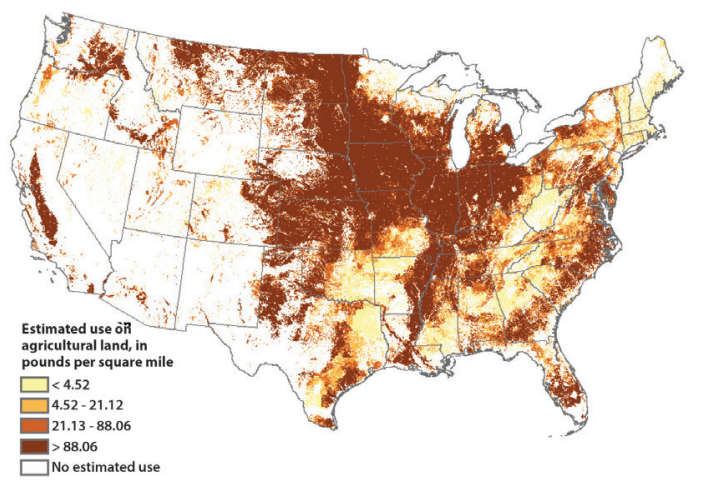

Figure 2. The estimated use of glyphosate for agricultural purposes in 2016 (preliminary, EPest-Low) (USGS, 2018).

Glyphosate, a herbicide used to kill broadleaf plants and grasses, is the most commonly used herbicide in the United States ("Glyphosate," 2019) (Figure 2). Exposure to glyphosate can occur when using the herbicide itself or in drinking water ("Glyphosate," 2019). The EPA set the MCL at 700 ppb in drinking water ("National primary," 1995). There is some question as to whether exposure to glyphosate can lead to developmental, reproductive, and carcinogenic effects among biological organisms ("Toxicological summary," 2017).

Nanoparticles are synthesized materials where at least one dimension is less than $100 \mathrm{~nm}$ (Khan, Saeed, \& Khan, 2017; Laurent et al., 2008). Nanotechnology itself is a booming business worth up to trillions of dollars in various sectors such as chemistry, electronics, and medicine (Chakraborty, Sharma, Sharma, \& Lee, 2016). Nanoparticles are also common in everyday products such as paint, food, and cosmetics (Sajid et al., 2014).

Graphene is a crystalline form of carbon where the atoms are arranged in a hexagonal pattern (Park et al., 2014) (Figure 3). Graphene is strong and lightweight and is known to conduct electricity and heat (Park et al., 2014). Since its discovery, graphene has been applied for various purposes such as energy storage, biosensors, biomedicine, and electronics (Park et al., 2014). Graphene itself has the potential to be used for environmental remediation purposes (Amir et al., 2016). Specifically, graphene has a high adsorption capacity for pollutants found in air and water due to the presence of strong $\pi-\pi$ interactions (a noncovalent interaction) (Wang, Sun, Ang, \& Tadé, 2013). Furthermore, the efficacy of graphene could be due to its large surface area (Wang et al., 2013). Graphene nanoplatelets (GNPs) themselves are stacks

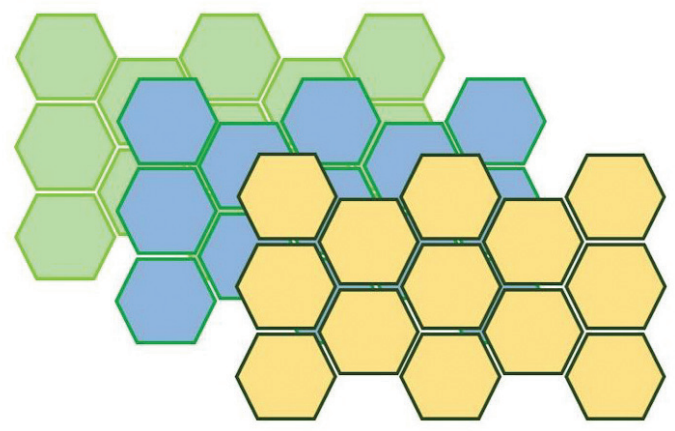

Figure 3. Representation of GNPs.

of parallel graphene layers that have a thickness of less than $100 \mathrm{~nm}$ (Chen et al., 2012).

\section{MATERIALS AND METHODS}

\section{Atrazine Binding Experimental Methods}

For the atrazine binding experiment, different mixtures of GNPs and atrazine were first prepared in glass vials as shown in Table 1. An atrazine solution (CAS 1912-24-9, Chem Service, West Chester, PA) of $6 \mathrm{ppb}(\mu \mathrm{g} / \mathrm{L})$ was made by diluting a $10,000 \mathrm{ppb}$ atrazine stock solution with deionized water using appropriate volumes and concentrations determined using the equation $\mathrm{M}_{1} \mathrm{~V}_{1}=\mathrm{M}_{2} \mathrm{~V}_{2}$. Initially, the GNP solutions were created at double the desired final concentration $(1,2,4$, and $6 \mathrm{mg} / \mathrm{ml})$. Next, $1.5 \mathrm{ml}$ of the atrazine solution and $1.5 \mathrm{ml}$ of the appropriate GNP solution were combined in order to have a final volume of $3 \mathrm{ml}$ in each glass vial (Figure 4). As a result, the concentration of atrazine became $3 \mathrm{ppb}$, and the concentrations of GNPs became $0.5,1,2$, or 3 $\mathrm{mg} / \mathrm{ml}$ in the glass vials. The samples were incubated

\begin{tabular}{|l|l|}
\hline $\begin{array}{l}\text { GNP Concentration } \\
\text { (N-GNP, COOH, NH2) }\end{array}$ & $\begin{array}{l}\text { Atrazine } \\
\text { Concentration }\end{array}$ \\
\hline $0 \mathrm{mg} / \mathrm{ml}$ & $3 \mathrm{ppb}$ \\
\hline $0.5 \mathrm{mg} / \mathrm{ml}$ & $3 \mathrm{ppb}$ \\
\hline $1 \mathrm{mg} / \mathrm{ml}$ & $3 \mathrm{ppb}$ \\
\hline $2 \mathrm{mg} / \mathrm{ml}$ & $3 \mathrm{ppb}$ \\
\hline $3 \mathrm{mg} / \mathrm{ml}$ & $3 \mathrm{ppb}$ \\
\hline $3 \mathrm{mg} / \mathrm{ml}$ & $0 \mathrm{ppb}$ \\
\hline
\end{tabular}

Table 1. Table of all the mixtures used in the atrazine binding experiment. 


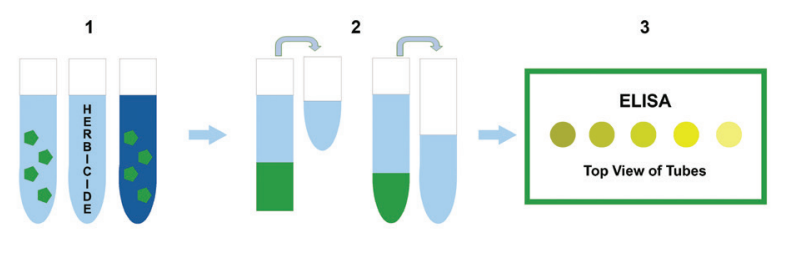

Figure 4. Summarized flowchart of the protocol for the binding experiments. Step 1 involves creating different samples in glass vials and incubating them for 24 hours on a rotating apparatus. Step 2 involves centrifuging the samples and removing the supernatant twice. Step 3 involves assessing the supernatant for unbound atrazine and glyphosate using the Abraxis atrazine and glyphosate ELISA assays, respectively.

at room temperature for 24 hours on a rotating apparatus. Each sample from the glass vials was then transferred to a Falcon tube, and all the tubes were centrifuged for 20 minutes at 4,000 rpm and 28 degrees Celsius. Afterward, $1.2 \mathrm{ml}$ of the supernatant was removed from each Falcon tube and placed in labeled microcentrifuge tubes. The microcentrifuge tubes were centrifuged for 30 minutes at 15,000 rpm and 28 degrees Celsius. Next, $400 \mu 1$ of the supernatant was removed from each microcentrifuge tube and placed in a new microcentrifuge tube to be stored in the refrigerator at 4 degrees Celsius until analysis. The Abraxis Atrazine ELISA assay was performed following manufacturer recommendations. Absorbance values at $450 \mathrm{~nm}$ were obtained using a Nanodrop. A standard curve was created to determine the concentrations of unbound atrazine in the samples. A subtractive method was then used to calculate the percent of atrazine bound to the GNPs. Statistical analysis was carried out using One-way analysis of variance (ANOVA) with a Tukey's post hoc test $(\alpha<0.05)$.

\section{Atrazine Dissociation Experimental Methods}

Dissociation experiments were carried out to determine the strength of the bond between atrazine and GNPs, specifically the nonfunctionalized GNPs (N-GNPs). First, the appropriate solutions were created in glass vials: (1) 3 ppb atrazine, no GNPs, and (2) $3 \mathrm{ppb}$ atrazine, $2 \mathrm{mg} / \mathrm{ml}$ of N-GNPs. An atrazine solution at $6 \mathrm{ppb}$ was prepared as described above. The GNP solutions were made at $4 \mathrm{mg} / \mathrm{ml}$. In order to get a final volume of $3 \mathrm{ml}$ of each solution in the glass vials, $1.5 \mathrm{ml}$ of the atrazine solution and $1.5 \mathrm{ml}$ of the GNP solution (or $1.5 \mathrm{ml}$ of deionized (DI) water if no GNPs were added) were added into each glass vial. As a result, the final concentrations of the solutions became $3 \mathrm{ppb}$ atrazine and $2 \mathrm{mg} /$ ml GNPs (if GNPs were added). All mixtures were vortexed, incubated, and centrifuged using the same steps that were followed in the atrazine binding experimental methods with the supernatant samples (referred to as Set 1). Further specific to this experiment, remaining GNP pellets were dispersed in $2 \mathrm{ml}$ of DI water. Samples were centrifuged for 20 minutes at 5,000 rpm and 28 degrees Celsius, and the supernatant was removed. This step was repeated and then GNPs resuspended in fresh $3 \mathrm{ml}$ of DI water by vortexing for at least 15 seconds and pipetting up and down. Samples were then incubated at room temperature on the rotating apparatus for 24 hours. Following incubation, centrifugation was repeated and $1.4 \mathrm{ml}$ of supernatant removed from each tube and centrifuged for 15 minutes at 15,000 rpm in a new tube. Next, $400 \mu$ l of supernatant was transferred to a new tube (considered as Set 2). Atrazine concentration of each sample was determined using the Abraxis Atrazine ELISA assay following manufacturer recommendations. A subtractive method was used to determine the percent atrazine bound to the GNPs. Statistical analysis was carried out using a t-test to compare Sets 1 and $2(\alpha<0.05)$.

\section{Atrazine and Glyphosate Binding Experimental Methods}

For the second binding experiment, different treatments of N-GNPs, glyphosate (CAS 1071-83-6, West Chester, PA), and atrazine were first prepared in glass vials (Table 2; see Figure 4). An atrazine solution of $9 \mathrm{ppb}$ was prepared similar to what was described above. A glyphosate solution was prepared at 2,100 ppb. The GNP solutions were created at $3 \mathrm{mg} / \mathrm{ml}$. Next, $1 \mathrm{ml}$ of each solution (atrazine + glyphosate + GNPs) was combined in order to have a final volume of $3 \mathrm{ml}$ in each glass vial (Table 2). As a result, the concentration of atrazine became 3 ppb, glyphosate $700 \mathrm{ppb}$, and N-GNPs $1 \mathrm{mg} / \mathrm{ml}$. The samples were incubated at room temperature for 24 hours on a rotating apparatus, transferred to a Falcon tube, and centrifuged for 20 minutes at 4,000 rpm and 28 degrees Celsius. Next, $1.0 \mathrm{ml}$ of the supernatant was removed and placed in a microcentrifuge tube. Tubes were centrifuged for 30 minutes at 15,000 rpm and 28 degrees Celsius. Then, $400 \mu 1$ of the supernatant was removed, placed in a new tube, and stored in the refrigerator until analysis. Atrazine and glyphosate concentrations were determined using the Abraxis Atrazine ELISA or the Abraxis Glyphosate 


\begin{tabular}{|l|l|l|l|l|l|}
\hline Samples & Type & N-GNPs & Atrazine & Glyphosate & DI H20 \\
\hline 1 & Control & X & $X$ & X & $3 \mathrm{ml}$ \\
\hline $2-5$ & GNPs only & $1 \mathrm{ml}$ & $X$ & $X$ & $2 \mathrm{ml}$ \\
\hline $6-9$ & ATZ only & $X$ & $1 \mathrm{ml}$ & $X$ & $2 \mathrm{ml}$ \\
\hline $10-13$ & GLY only & $X$ & $X$ & $1 \mathrm{ml}$ & $2 \mathrm{ml}$ \\
\hline $14-17$ & GNP+ATZ & $1 \mathrm{ml}$ & $1 \mathrm{ml}$ & $X$ & $1 \mathrm{ml}$ \\
\hline $18-21$ & GNP+GLY & $1 \mathrm{ml}$ & $X$ & $1 \mathrm{ml}$ & $1 \mathrm{ml}$ \\
\hline $22-25$ & GNP+ATZ+GLY & $1 \mathrm{ml}$ & $1 \mathrm{ml}$ & $1 \mathrm{ml}$ & $X$ \\
\hline
\end{tabular}

Table 2. Table of different mixtures for second binding experiment.

ELISA assay, respectively, following manufacturer protocols. Statistical analysis was carried out using a one-way ANOVA with a Dunnett's multiple comparison test $(\alpha<0.05)$.

\section{RESULTS}

\section{Atrazine Binding Experiment}

In the atrazine binding experiment, a subtractive method was implemented in order to find the percent of atrazine bound to the different GNPs since the assay detected the unbound atrazine left in the supernatant. After subtracting the amount of atrazine present in the supernatant from the total amount of atrazine in each mixture, it was possible to determine the actual percent of atrazine bound to the GNPs (Figure 5). After graphing the results, it was found that all the GNPs at $3 \mathrm{mg} / \mathrm{ml}$ were not statistically different from the previous dose of $2 \mathrm{mg} /$ $\mathrm{ml}(\mathrm{p}>0.05)$; this means that as the concentration

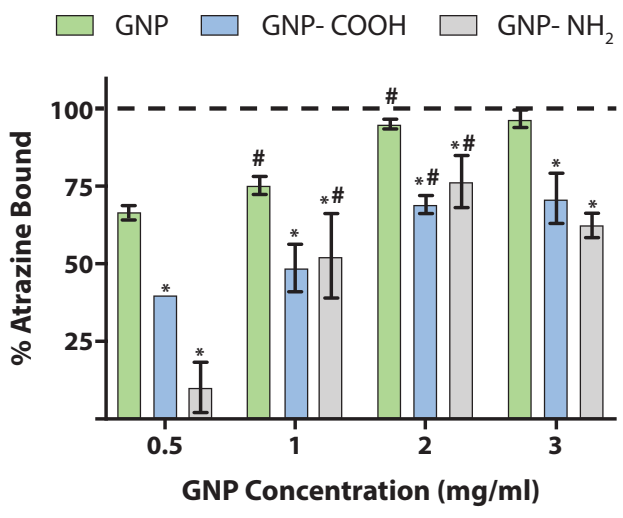

Figure 5. Atrazine binding experiment. *Signifies statistically different from N-GNP at $\mathrm{p}<0.05$ ); \#Signifies statistically different from previous dose at $\mathrm{p}<0.05, \mathrm{~N}=4$; Error bars represent standard deviation. of GNPs increased, the percent of atrazine bound increased as well until there was a plateau at 2-3 $\mathrm{mg} / \mathrm{ml}$ GNPs. Furthermore, the results showed that both the carboxylated and aminylated GNPs at all concentrations were statistically different from the $\mathrm{N}-\mathrm{GNPs}$, indicating that the N-GNPs bound most efficiently to atrazine $(\mathrm{p}<0.05)$.

\section{Atrazine Dissociation Experiment}

The atrazine ELISA assay detected the concentration of unbound atrazine present in the supernatant from Set 1 and Set 2; therefore, the subtractive method was implemented again in order to determine the percent of atrazine bound to the N-GNPs (Figure 6). After graphing the results from the dissociation experiment, it was determined that both bars were not statistically different from each other; thus, almost all of the atrazine remained bound to the $\mathrm{N}-$ GNPs after resuspension in deionized water $(\mathrm{p}>0.05)$.

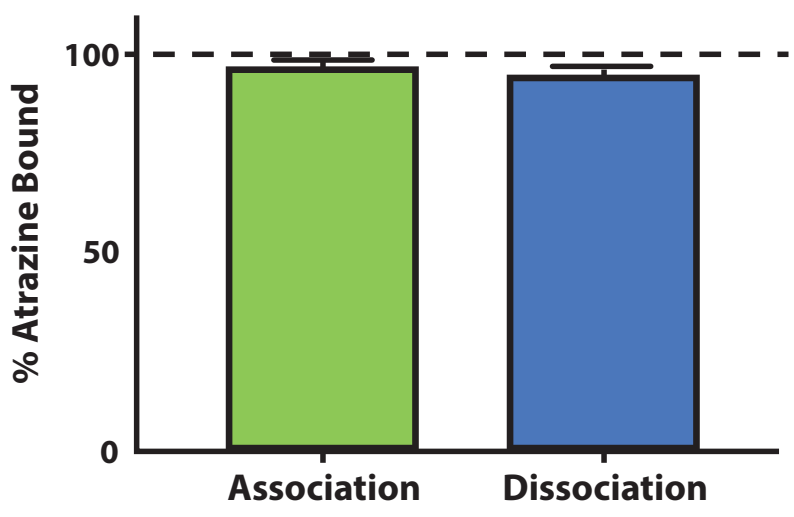

Figure 6. Atrazine dissociation experiment. $N=4, p>0.05$; Error bars represent standard deviation. 


\section{Atrazine and Glyphosate Binding Experiment}

The second binding experiment tested whether glyphosate would bind to GNPs and whether an interaction would occur in a mixture of atrazine and glyphosate. The concentration of atrazine in the GNPs-only mixture was near zero and statistically different from the ATZ-only mixture, indicating that the GNPs did not interfere in the atrazine assay (Figure 7a); this same concept applies to the GLY-only and the GNP + GLY mixtures. Both the GNP + ATZ and GNP + ATZ + GLY mixtures were statistically different from the ATZ-only mixture $(\mathrm{p}<0.05)$, indicating that there was less atrazine detected in the supernatant of the first two mixtures mentioned. Thus, some of the atrazine from the first two mixtures had bound to the N-GNPs. More importantly, both the GNP + ATZ and the GNP + ATZ + GLY mixtures were not statistically different from each other $(\mathrm{p}>$ 0.05 ), indicating that the presence of glyphosate does not interfere with the binding between atrazine and the N-GNPs.

In the glyphosate ELISA assay, the concentration of glyphosate in the three mixtures with GNPs only, ATZ only, and GNP + ATZ were all near zero and statistically different from the GLY-only mixture $(\mathrm{p}<0.05)$, indicating that the assay did not detect a significant amount of glyphosate in their supernatants (Figure 7b). However, the mixtures with GNP + GLY and GNP + ATZ + GLY were not statistically different from the GLY-only mixture $(\mathrm{p}>0.05)$, indicating that these two mixtures had a significant amount of glyphosate detected in the supernatant. Furthermore, the glyphosate in these two mixtures did not bind to the GNPs.

\section{DISCUSSION}

Atrazine and glyphosate are heavily used agricultural herbicides in the United States (Fakhouri et al., 2010; "Glyphosate," 2019). Both herbicides are detected in drinking water at varying levels, thus posing a potential risk for human exposure (Gilliom et al., 2006; Thurman et al., 1991; "Glyphosate," 2019). The EPA is responsible for regulating many pesticides in the United States ("About pesticide," 2018). In terms of risks, atrazine and glyphosate are possibly linked to endocrine, developmental, reproductive, and/ or carcinogenic effects ("Toxicological summary," 2017; Wirbisky et al., 2016). As a result, there is a need to develop ways to remediate or clean up atrazine and glyphosate contamination in drinking water sources. Current literature indicates that GNPs could potentially be applied for environmental remediation purposes (Amir et al., 2016). Graphene's a.

ATRAZINE ASSAY

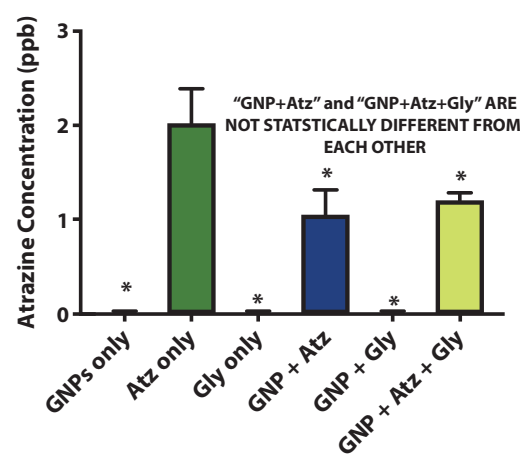

b.

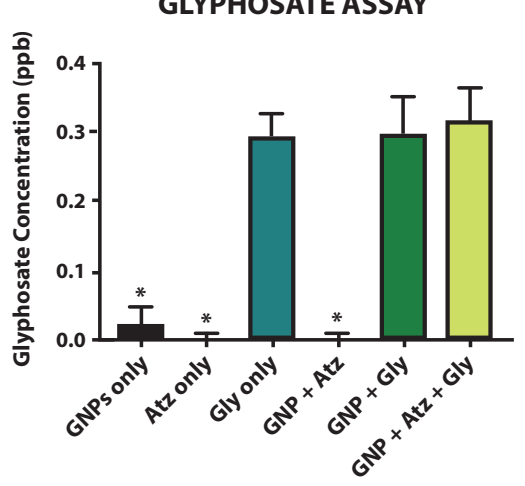

Figures $\mathbf{7 a}$ and $\mathbf{7 b}$. Atrazine and glyphosate binding experiment. (A) Atrazine concentration of supernatant. (B) Glyphosate concentration of supernatant. $N=4,{ }^{*} p<0.05$; Error bars represent standard error.

high surface area allows it to attach to contaminants and be chemically modified (Sweetman et al., 2017). These qualities make graphene an attractive option for water purification purposes (Sweetman et al., 2017). Current research has focused on the possibility of graphene being used in the form of size exclusion filtration membranes (Sweetman et al., 2017). Furthermore, graphene is typically chemically converted into graphene oxide, which integrates a hydrophilic nature to the nanoparticles, thereby increasing water flow through the graphene oxide nanoparticles (Sweetman et al., 2017). Research shows that graphene oxide membranes have the ability to filter organic compounds of various sizes (Sweetman et al., 2017).

Data from the first binding experiment showed that as the concentration of the GNPs increased, the percent of atrazine bound increased as well until it plateaued at $2-3 \mathrm{mg} / \mathrm{ml}$ GNPs. Furthermore, the N-GNPs bound more to atrazine than the other functionalized GNPs. Results from the dissociation experiment showed that almost all of the atrazine remained bound to the N-GNPs. Therefore, the N-GNPs appear to be the most effective kind of 
GNP in terms of binding to atrazine. This indicates that these nanoparticles may possibly be a mode of capturing atrazine present in drinking water.

Data from the second binding experiment showed that the N-GNPs still bound to atrazine even in the presence of glyphosate, indicating that glyphosate did not interfere in the binding between atrazine and the N-GNPs. Furthermore, the N-GNPs did not bind to glyphosate. Overall, the data indicates that there is a possibility that GNPs are attracted to aromatic ring structures. This is important in informing researchers that the N-GNPs can best target and bind to herbicides with aromatic rings (such as atrazine) found in the environment, specifically in drinking water sources for remediation.

\section{ACKNOWLEDGMENTS}

All research occurred under the supervision of Dr. Jennifer Freeman and Dr. Jonathan Shannahan, along with assistance from Katharine Horzmann (previous laboratory member and graduate student). Nudar Bhuiya was supported by Purdue's Office of Undergraduate Research and the Purdue Honors College.

\section{REFERENCES}

About pesticide registration. (2018). Retrieved from https:// www.epa.gov/pesticide-registration/about-pesticide-registration

Amir, A., Mahalingam, S., Wu, X., Porwal, H., Colombo, P., Reece, M., \& Edirisinghe, M. (2016). Graphene nanoplatelets loaded polyurethane and phenolic resin fibres by combination of pressure and gyration. Composites Science and Technology, 129, 173-182. doi:10.1016/j. compscitech.2016.03.031

Atrazine. (2019). Retrieved from https://pubchem.ncbi.nlm. nih.gov/compound/atrazine\#section=Top

Chakraborty, C., Sharma, A. R., Sharma, G., \& Lee, S. (2016). Zebrafish: A complete animal model to enumerate the nanoparticle toxicity. Journal of Nanobiotechnology, 14(1). Retrieved from https://jnanobiotechnology.biomedcentral.com/articles/10.1186/s12951-016-0217-6

Chen, L., Konishi, H., Fehrenbacher, A., Ma, C., Xu, J., Choi, H., . . . Li, X. (2012). Novel nanoprocessing route for bulk graphene nanoplatelets reinforced metal matrix nanocomposites. Scripta Materialia, 67(1), 29-32. doi:10.1016/j. scriptamat.2012.03.013

European Commission. (2013). Herbicide levels in coastal waters drop after EU ban. Retrieved from http://ec.europa.eu/environment/integration/research/newsalert/ pdf/349na2_en.pdf

Fakhouri, W., Nuñez, J., \& Trail, F. (2010). Atrazine binds to the growth hormone-releasing hormone receptor and affects growth hormone gene expression. Environmental Health Perspectives, 118(10), 1400-1405.

Gilliom, R., Geological Survey, \& National Water-Quality Assessment Program. (2006). Pesticides in the nation's streams and ground water, 1992-2001: The quality of our nation's waters (Rev. Feb. 15, 2007. ed. U.S. Geological Survey circular, 1291). Reston, VA: U.S. Geological Survey.

Glyphosate. (2019). Retrieved from http://npic.orst.edu/factsheets/glyphogen.html

Khan, I., Saeed, K., \& Khan, I. (2017). Nanoparticles: Properties, applications and toxicities. Arabian Journal of Chemistry. doi:10.1016/j.arabjc.2017.05.011

Laurent, S., Forge, D., Port, M., Roch, A., Robic, C., Elst, L. V., \& Muller, R. N. (2008). Magnetic iron oxide nanoparticles: Synthesis, stabilization, vectorization, physicochemical characterizations, and biological applications. Chemical Reviews, 108(6), 2064-2110. doi:10.1021/ cr068445e

National primary drinking water regulations: Glyphosate. (1995). Retrieved from https://nepis.epa.gov/Exe/ZyPDF. cgi/9100PO3S.PDF?Dockey=9100PO3S.PDF

Park, E., Lee, G., Han, B. S., Lee, B., Lee, S., Cho, M., .. . Kim, D. (2014). Toxic response of graphene nanoplatelets in vivo and in vitro. Archives of Toxicology, 89(9), 1557-1568. doi:10.1007/s00204-014-1303-x

Sajid, M., Ilyas, M., Basheer, C., Tariq, M., Daud, M., Baig, N., \& Shehzad, F. (2014). Impact of nanoparticles on human and environment: Review of toxicity factors, exposures, control strategies, and future prospects. Environmental Science and Pollution Research, 22(6), 4122-4143. doi:10.1007/s11356-014-3994-1

Sweetman, M. J., May, S., Mebberson, N., Pendleton, P., Vasilev, K., Plush, S. E., \& Hayball, J. D. (2017). Activated carbon, carbon nanotubes and graphene: Materials and composites for advanced water purification. C, 3(2). doi:http://dx.doi.org/10.3390/c3020018

Thurman, E. M., Goolsby, D. A., Meyer, M. T., \& Kolpin, D. W. (1991). Herbicides in surface waters of the midwestern United States: The effect of spring flush. Environmental Science \& Technology, 25(10), 1794-1796. doi:10.1021/ es00022a018

Toxicological summary for: Glyphosate. (2017). Retrieved from https://www.health.state.mn.us/communities/environment/risk/docs/guidance/gw/glyphosatesumm.pdf

USGS. (2018). Estimated annual agricultural pesticide use. Retrieved from https://water.usgs.gov/nawqa/pnsp/ usage/maps/show_map.php?year=2016\&map=ATRAZINE\&hilo=L\&disp=Atrazine

USGS. (2018). Estimated annual agricultural pesticide use. Retrieved from https://water.usgs.gov/nawqa/pnsp/usage/ maps/show_map.php?year=2016\&map=GLYPHOSATE \&hilo $=$ L\&disp $=$ Glyphosate

Wang, S., Sun, H., Ang, H. M., \& Tadé, M. O. (2013). Adsorptive remediation of environmental pollutants using novel graphene-based nanomaterials. Chemical Engineering Journal, 226, 336-347. https://doi.org/10.1016/j. cej.2013.04.070

Wirbisky, S. E., Weber, G. J., Sepúlveda, M. S., Lin, T., Jannasch, A. S., \& Freeman, J. L. (2016). An embryonic atrazine exposure results in reproductive dysfunction in adult zebrafish and morphological alterations in their offspring. Scientific Reports,6. doi:10.1038/srep21337

Wirbisky, S. E., Weber, G. J., Sepúlveda, M. S., Xiao, C., Cannon, J. R., \& Freeman, J. L. (2015). Developmental origins of neurotransmitter and transcriptome alterations in adult female zebrafish exposed to atrazine during embryogenesis. Toxicology, 333, 156-167. http://doi. org/10.1016/j.tox.2015.04.016 